\title{
Macrothink
}

\section{Four Effective Actions of Teacher Participation in Training}

\author{
Fanming Meng (Corresponding author) \\ Lvliang Hechang Middle School \\ 1 Hechang Road, Lishi District, Lvliang City, Shanxi Province, China \\ E-mail: mfm2009@126.com
}

Received: December 21, 2020 Accepted: December 30, 2020 Published: January 11, 2021

doi:10.5296/ijld.v10i4.18191

URL: https://doi.org/10.5296/ijld.v10i4.18191

This paper is the research result of the "Research on the Professional Development of Middle School Political Teachers", a subject of the 12th Five-Year Plan of Education Science in Shanxi Province. The subject number is GH-14124.

\begin{abstract}
In a people-oriented education system in China, teachers need to be treated as complete human beings. This not only requires teachers to master the relevant educational technology, but also to update their own educational ideas. The teacher training has become an important way for teachers to adapt to the development of online education. As the main body of the training activities, primary and secondary school teachers should (1) act as learners, (2) be fully prepared for learning, (3) attach importance to professional writing and (4) build a learning community.
\end{abstract}

Keywords: teachers' initiative development, the professional writing, the professional confidence, the learning community

\section{Introduction}

\subsection{The Problem of Teacher Training that Ignores Teachers' Subjectivity}

In educational reform in the digital economy, China needs to refocus on teachers as a key factor. Teacher training can effectively promote teacher professional development. Because it is not only the interests of teachers, but also an important way for schools to improve the teaching quality. The teacher professional development is the result of teachers' internal motivation and external resources. Teachers' development does need external professional 
drive, but it is very important for teachers' professional development to respect teachers' subjectivity and developing teachers' learning motivation in the teacher training. Any external educational resources must be recognized by teachers to play an effective role. The research object of this paper is primary and secondary school teachers in China.

The teacher training organized by schools does improve the professional quality of primary and secondary school teachers to a certain extent, but it also faces a bottleneck. These activities fail to understand the particularity of teachers as adult learners and ignore the main role of teachers as learners. In this case, teachers just passively participate in it, which is likely to lead to formalism and inefficiency. In addition to effective organization and management, it is critical that the teacher training can obtain the necessary recognition and acceptance from teachers. The teacher training is a human activity, not an accumulation of things. Teacher training must be recognized by teachers themselves. In a people-oriented education system, teachers need to be treated as complete human beings. The organization and management of most schools may lack sufficient trust and care for their teachers, and the management mode of treating teachers as machines has discouraged teachers' enthusiasm. If there is no real need and value recognition for training activities by teachers themselves, the teacher training will fail, which seems to be bustling. That kind of mandatory and indoctrinated training activities cannot promote the development of teacher training, which is a waste of social resources.

\subsection{The Superstition of Educational Technology as a Component of Teacher Training}

It is an important part of teacher training to require teachers to master advanced educational technology. Technological revolutions can often revolutionize industries. If the most advanced technology and equipment have been purchased, the whole industry will undergo a disruptive change. For example, in the automobile industry, with the purchase of automated production lines, the automatic production of cars can be achieved. However, in the field of education, we have found that despite the acquisition of advanced educational technology, our education can't produce the expected application effect as in other industries. This is mainly due to the special nature of education. Educational activities are neither professional nor unprofessional. Only human beings are the objects of education, while the objects of other industrial sectors are inanimate materials such as the steel. So complex educational activities cannot be automated by the technological revolution.

In the relationship between teaching and technology, we often fall into a misunderstanding, that our teaching must be good with the use of technology. This view holds that the technology determines the teaching quality, and the mastery of technology becomes the foundation of teaching improvement. This view of technological omnipotence must be reconsidered. Under the guidance of this point of view, the teacher training becomes technical training, and advanced technology controls teachers and students. We must guard against teachers and students becoming slaves ruled by technology. The first thing for teachers is to have their own ideas of education, so that the educational technology can serve for the realization of educational ideas, instead of being led by the educational technology.

We should get rid of the misunderstanding of technological determinism. The teacher training 
is not equal to the technical training. The purpose of teacher training is to change teachers' wrong educational concept and understand human nature correctly. If a teacher is satisfied with the convenience of educational technology without innovation in educational concept, he or she is still a traditional teacher in essence.

\section{Teachers should Act as Learners in the Teacher Training}

Different from vocational preparation of teacher education, the teacher training can play an important role in providing development support for in-service teachers, solving problems in daily educational practice, and improving educational rational thinking to meet the new requirements of curriculum reform. The top-down curriculum reform often leads in-service teachers to continuously improve their professional quality from the top-level design level to meet the requirements of curriculum reform. The continuous advancement of curriculum, the continuous revision of teaching materials and the constant reform of teaching force primary and secondary school teachers to renew themselves constantly. This requires teachers to transform their roles from a teacher to a learner. This transformation is the basic condition for the success of teacher training.

\subsection{The Importance of the Teacher's Role as a Learner in Teacher Training}

Primary and secondary school teachers who have been teaching for many years should consciously change their educational roles and realize the role transformation from an onstage teacher to an off-stage learner. This role transformation is not simply the transformation of educational space, but the transformation of educational concepts. Teachers who teach students should attach importance to educating themselves. Teachers must first receive education to realize the combination of student development and self-development. Teachers with rich experience are often trapped in the shackles of experiential education, thinking that the educational experience formed by long-term educational practice is enough to deal with various educational problems, but they do not consciously realize the conditionality and limitation of teaching experience. Because of the extreme complexity of educational practice, it is impossible for any so-called successful educational model to be popularized successfully, which requires teachers to realize the complexity of educational practice and consciously become reflective practitioners rather than skilled technicians.

The fundamental purpose of teacher training is to make teachers themselves aware of the limitations of educational experience, which requires teachers to always regard themselves as learners. As the main body of training activities, teachers make self-reflection with the help of external professional resources, constantly reconstruct their own educational thinking, transcend the limitations of educational experience, and gradually establish their own personal educational philosophy.

\subsection{A Simple Analysis about Teachers as Learners in the Teacher Training}

Teachers in primary and secondary schools should make use of the beneficial resources of teacher training to become active learners, reflecting on their existing experience and learning from peers and experts with the confusion and problems in daily teaching. Instead of sticking to the role of a teacher in daily teaching and being a passive recipient of teacher training, 
teachers should consciously change from a teacher to a learner. If teachers are still satisfied with experiential teaching, they cannot truly recognize the value of teacher training and participate in it with their own bodies. As a result, they may just passively accept a bunch of rigid theories and fail to effectively improve their daily teaching.

In order to make the training activities truly meet the needs of teachers, teachers themselves need to establish a conscious awareness of professional development, and consciously carry out professional cooperation with the help of training activities. A new study shows that the participation of teachers before training has an important impact on the training results (Zhang \& Wang, 2020). Therefore, schools should also attach great importance to the mobilization and guidance in the early stage of training, fully protect the teachers' right to know, choose and make decisions, and form a benign atmosphere for teacher development.

\section{Teachers should be Fully Prepared for Learning in the Teacher Training}

The learning of minors depends on a variety of textual materials and on the continued guidance of adults such as parents and teachers. As adults, in-service teachers have accumulated rich experience in the educational practice. As a result, the way teachers learn is self-oriented and practice-oriented. Teachers should fully realize the particularity of teacher learning. They should not only take daily educational reflection as the main way of self-study, but also rely on external development resources such as the teacher training.

\subsection{The Importance of Teacher Preparation before the Training}

In order to make the training have the positive infiltration of "I", teachers should make the necessary preparations before the training. The purpose of the necessary preparation here is to further clarify the specific learning needs of teachers themselves, rather than passively cater to the external training requirements. In other words, schools should establish the subjective needs and objective requirements of teachers, to make their teachers realize the transition from the blind passivity to the conscious initiative.

It is a common way of teacher training to invite peers and experts to give lectures, which promote teachers to learn the necessary educational theories. If teachers don't want to be passively spoon-fed, they should combine with the training manual to make material preparation for learning, such as a laptop, a flash disk, a camera, and make the professional preparation. The professional preparation work focuses on the collections and analyses of information, mainly understanding their own needs and the background of the experts. As learners, we can sort out the difficult problems in daily education and the educational achievements we have made to establish our own learning needs. In order to facilitate professional communication, the above questions and results are best presented in writing. We also need to understand the professional background and training theme of the training experts, as well as the general situation of other participants, to establish the expected goal of professional learning.

\subsection{Some Methods on how Teachers Prepare for Attending Lectures}

On the one hand, teachers should understand the topic of the lecture and master the 
pre-implicit knowledge. The topics and themes of lectures are often the hot and difficult issues in the current education reform, which are closely related to primary and secondary school teachers and reflect the logical thinking of expert lectures. For example, in the professional lecture on core literacy, we can ask a question about how to understand the three key terms of the literacy, the core literacy and the discipline core literacy, what is the relationship between the literacy and the knowledge, and so on. By clarifying these concepts and basic issues and activating their own educational experience, teachers can have an equal and effective dialogue with experts, otherwise they may just scratch the surface and follow them blindly. Without some background information relevant to the topic of the lecture, teachers may be too busy taking notes to think independently. Teachers passively accept some fragmentary, fashionable words and phrases, so that they cannot criticize the content of the lecture rationally.

On the other hand, it is necessary to understand the discipline background and research expertise of the training experts. Compared with self-study, the main value of teacher training lies in face-to-face communication. Training activities provide teachers with valuable opportunities to interact with experts and peers. Due to the busy teaching work, primary and secondary school teachers have little opportunity to get professional guidance from experts. In order to improve the effectiveness of communication with experts, teachers should know the experts' professional background and research expertise in advance. In this way, teachers can increase the close contact with experts to obtain more targeted professional guidance. Teachers can read the representative literature of experts in advance to understand their research expertise, and they can also think about the combination of experts' opinions and their own research problems, to prepare for face-to-face communication with experts. On the same frontier issues, the effect of reading literature is different from that of expert lectures. Due to different professional backgrounds, face-to-face communication can understand the innovative views of experts more directly and comprehensively, make the implicit information in the literature explicit, and establish professional identity. If necessary, teachers can also submit their articles to experts for direct and targeted professional guidance.

\section{Teachers should Attach Importance to Professional Writing in the Teacher Training}

If teachers make themselves content with copying expert lectures as training summaries, they may develop a mechanical understanding. Through the interaction of experts and peers, teachers can develop the sparks of ideas that are most valuable. This indicates that teachers not only have a breakthrough in the analysis of some problems, but also cultivate the germination of new thinking. This requires teachers to take notes and use what they have learned to guide their teaching, rather than blindly copy the training content. Therefore, teachers need to pay attention to professional writing.

\subsection{Professional Writing cannot be Separated from Theoretical Guidance}

Professional writing is the process of summarizing educational experience with theoretical guidance. The training content will not be automatically converted into teachers' own knowledge and experience, and the successful learning cannot be accomplished overnight, which requires teachers to take the initiative to digest and apply. The teacher training has two 
dimensions: the theoretical study and the practical observation. Among them, the purpose of theoretical learning is to improve teachers' daily educational practice, rather than blindly learn the educational theory. Teachers need to grasp the theoretical content of training lectures from the whole system, rather than be satisfied with mastering some specific content. The vitality of theory lies in its ability to guide practice and help teachers to clarify the inadequacies and limitations of teaching experience. Combined with their own practical confusion, teachers carry out the necessary application. To some extent, learning through lectures is very preliminary. Teachers can further collect and read relevant literature and record difficult problems as a starting point for further learning. Teachers carry out professional writing in order to deeply digest the training content under the guidance of theoretical thinking.

\subsection{Some Thoughts about Teachers'Professional Writing}

Professional writing is an effective way to creatively study and apply educational theories. Different from the simple summary of experience, teachers take the theoretical inspiration gained from the training as an opportunity to think logically and write research papers. The main achievement of the teaching research is to form a logical, innovative and readable paper. In paper writing, there are two main types of writing logic. The first one is the logical induction of teaching experience, which follows the path from individual things to general rules. Teachers analyze their own teaching arguments, by focusing on the establishment, expression, solution and verification of a certain problem or problem chains in the daily teaching, such as the lesson preparation, the teaching, the lecture and the examination, etc. The second one is the deductive reasoning of educational theory. It follows the ideas of general rules to individual things, extends the disciplinary and professional theories to specific teaching practice, guides teaching reflection with theories, or carries out new teaching attempts according to the theoretical requirements (Meng, 2020). In a word, professional writing should be an important way for teachers' professional development. Teachers should try to write professional papers in order to sort out their own teaching process and summarize their own teaching experience.

\section{Teachers Should Build a Learning Community by the Teacher Training}

Only when training activities really meet the key issues of teacher development and meet the diversified needs of teachers, against the external pressure of education administration, training activities can really attract teachers to devote themselves to them. The teacher training is not only to perfect the teachers' professional deficiency, but also to play the teachers' professional strength. Teacher training based on teacher active development needs to establish a real learning community.

\subsection{Schools should Establish the Concept of Learner-centered Training}

Schools should adhere to the concept of learner-centered training, investigate the current situation of teacher development, clarify the objectives and contents of teacher training, consider the characteristics of adult learning and teachers' profession, and establish effective training methods (Zhu \& Chang, 2018). In order to realize continuous education reform, the 
teacher training should not stay on the short-term commercial effect. It should fully consider the complexity of teachers' learning and accurately grasp the real needs of teachers, rather than simply cater to the needs of teachers, and design a basic, professional and systematic curriculum system (Song, 2018). On the one hand, it is necessary to perfect the school-based research mechanism, establish effective teaching and research system, and give play to the professional role of the academic staff; on the other hand, it is also necessary to carry out the cooperation between universities and primary and secondary schools, and build teacher development schools as the learning community.

It should be noted that college teachers and primary and secondary school teachers are in a cooperative relationship, and the theoretical research of educational theorists needs the support of teaching experiments in primary and secondary schools, and the teachers also need the theoretical guidance of educational theorists. College experts should fully understand the important value of basic education work, respect the educational experience of primary and secondary school teachers, help them to carry out professional reading and professional writing, and improve the existing professional practice.

\subsection{Teachers should Enhance Their Confidence in Professional Development}

As the main body of training activities, primary and secondary school teachers need to establish confidence in professional development and recognize the important value of basic education work and subject teaching. Teachers are also fully aware of the favorable conditions and limitations of the development of primary and secondary school teachers and take the initiative to improve the rational thinking of education. The educational research is not the patent of university experts. Primary and secondary school teachers can and must also engage in educational researches. They should understand the trends of research frontier, capture the hot issues of education, update themselves with the theoretical guidance of curriculum experts, and constantly expand the learning community.

When facing experts and peers, many teachers show inferiority and arrogant attitude. This is likely to cut off the possibility of professional communication. For this reason, teachers must consciously recognize their professional value and professional expertise, and can't deny themselves because of temporary difficulties and limitations. Teachers must also be aware of the urgency of teachers' lifelong learning and cannot blindly deny the necessity of learning from others because of temporary victories and achievements.

\section{Conclusion}

In the post-epidemic era, online education is developing rapidly in all countries. The rapid development of online education has greatly satisfied the needs of students' personalized learning. This not only requires teachers to master the relevant educational technology, but also to update their own educational ideas. Learning is a teacher's lifelong career. Teachers should pay attention to the development of students, as well as the society and the world, and integrate their own development into the current era. The world today is full of uncertainties, which calls for teachers' wisdom and responsibility to build a free and happy life.

The teacher training has become an important way for teachers to adapt to the development 


\section{Macrothink

of online education. As the main body of the training activities, primary and secondary school teachers in China should act as learners, be fully prepared for learning, attach importance to professional writing and build a learning community.

There are still many shortcomings in this paper due to the author's limited research ability. This article does not refer sufficiently to the latest research papers on teacher training issues in other countries. As a matter of fact, the teacher training is a hot topic of education research in other countries, which have produced a lot of research achievements and achieved good practical results. Many of the arguments in this article are not logical enough, which may lead to some misunderstandings for the reader. The research method of this paper is very simple and unconvincing, so the investigation method should be adopted. The above shortcomings of this paper clarify the direction of further research in the teacher training.

\section{References}

Meng, F. (2020). Ideological and Political Course Teachers' Educational Rationality. Journal of Education and Culture Studies, 4(4), 128-135. https://doi.org/10.22158/jecs.v4n1p128

Song, L. (2018). The Practical Crisis and Response of "Needs-oriented" Teacher Training. Educational Theory and Practice, 38(28), 43-47.

Zhang, Q., \& Wang, H. (2020). An Empirical Study on the Impact of Teachers' Early Participation on Training Effectiveness. Chinese Journal of Education, (4), 91-96.

Zhu, Z., \& Chang, B. (2018). Learner Center: The Transformation and Development of Teacher Training in Primary and Secondary Schools. Chinese Journal of Education, (4), 76-80.

\section{Copyright Disclaimer}

Copyright for this article is retained by the author(s), with first publication rights granted to the journal.

This is an open-access article distributed under the terms and conditions of the Creative Commons Attribution license (http://creativecommons.org/licenses/by/4.0/). 